\title{
Intrinsic myocardial recovery from the negative inotropic effects of acute hypercapnia
}

\author{
P. FÖ̈X ${ }^{1}$ and R. M. M. FORDHAM \\ From the Nuffield Department of Anaesthetics, Radcliffe Infirmary, Oxford
}

\begin{abstract}
AUTHORS' SYNOPSIS The inotropic effects of hypercapnia have been examined in the isometric papillary muscle preparation from the cat. The initial stage of depression which resulted from the acute induction of hypercapnia was followed by a significant degree of spontaneous recovery during the next hour. When the carbon dioxide concentration was returned to normal a temporary rebound in performance to well above control levels was observed. These findings are interpreted as being due to slow changes arising within heart muscle itself which partially compensate for the direct inotropic depressant effect of hypercapnia.
\end{abstract}

It is firmly established that heart muscle is depressed by high levels of carbon dioxide $\left(\mathrm{CO}_{2}\right)$, and that its performance is enhanced in the presence of a low carbon dioxide level (Boniface and Brown, 1953; Nahas, 1957; McElroy, Gerdes, and Brown, 1958; Ng, Levy, and Zieske, 1967; Noble, Trenchard, and Guz, 1967; Caress, Kissack, Slovin, and Stuckey, 1968; Pannier and Leusen, 1968). During the course of a study on the acute effects of $\mathrm{CO}_{2}$ on the cat papillary muscle preparation we observed that, following the initial stage of depression seen after the $\mathrm{CO}_{2}$ concentration was acutely raised, some recovery in performance appeared to occur. This paper describes the studies we have made to confirm this observation.

\section{Methods}

Nine experiments were performed in eight isometric right ventricular papillary muscle preparations from the cat. After the induction of anaesthesia with nitrous oxide, oxygen, and halothane $(2-2.5 \%)$, the heart was rapidly excised and immersed in oxygenated Ringer-phosphate-bicarbonate solution at room temperature. One minute later the beating heart was removed from the solution, the right ventricle opened, a suitable papillary muscle selected, and a short length of $4 / 0$ non-capillary

${ }^{1}$ Dr. P. Foëx was supported by a grant from the Hôpital Cantonal et Universitaire, Geneva, and by a special grant from the Holderbank Stiftung, Aargau, Switzerland. braided thread tied to its upper end. The muscle was then detached from the ventricular wall and placed in position in a temperature controlled muscle bath. Experiments were performed at temperatures of $19-23^{\circ} \mathrm{C}$ and in any single experiment was kept constant to within $0 \cdot 2^{\circ} \mathrm{C}$. The solution in which the muscle was immersed was of the following composition $(\mathrm{m}-\mathrm{mole} / \mathrm{l}.) ; \quad \mathrm{NaCl}=119 \cdot 4, \quad \mathrm{KCl}=4.8$, $\mathrm{MgSO}_{4}=1 \cdot 2, \quad \mathrm{CaCl}_{2}=2 \cdot 6, \quad \mathrm{NaH}_{2} \mathrm{PO}_{4}=1 \cdot 2$, $\mathrm{NaHCO}_{3}=29.5$ with glucose $100 \mathrm{mg} \%$. The $\mathrm{pH}$ of the solution was measured with a microelectrode and $\mathrm{pH}$ meter (Radiometer PHM27GM) maintained at the same temperature as the muscle bath. The solution was continuously equilibrated with one of two gas mixtures containing either $4.67 \%$ or $9.79 \%$ carbon dioxide in oxygen.

The upper end of the muscle was attached by the braided thread to a heavily counter-weighted lever and the initial length of the muscle was set by a micrometer gauge which impinged on the upper surface of the tip of the lever. The lower end of the muscle was held in a light clip fixed to a stainless steel rod which passed through a mercury seal in the bottom of the bath to a Devices 2STO2 tension transducer. The transducer was energized from a Tektronix type ' $Q$ ' strain gauge pre-amplifier. The rate of force development $(\mathrm{dF} / \mathrm{dt})$ was obtained by differentiating the force signal on the principles described by Gersh, Hahn, and Prys-Roberts (1971), the gain of the differentiator being linear between frequencies of 0 to $10 \mathrm{~Hz}$. Both the force and the $\mathrm{dF} / \mathrm{dt}$ signals were displayed on a Tektronix dual beam oscilloscope (Model 556), and also on a 


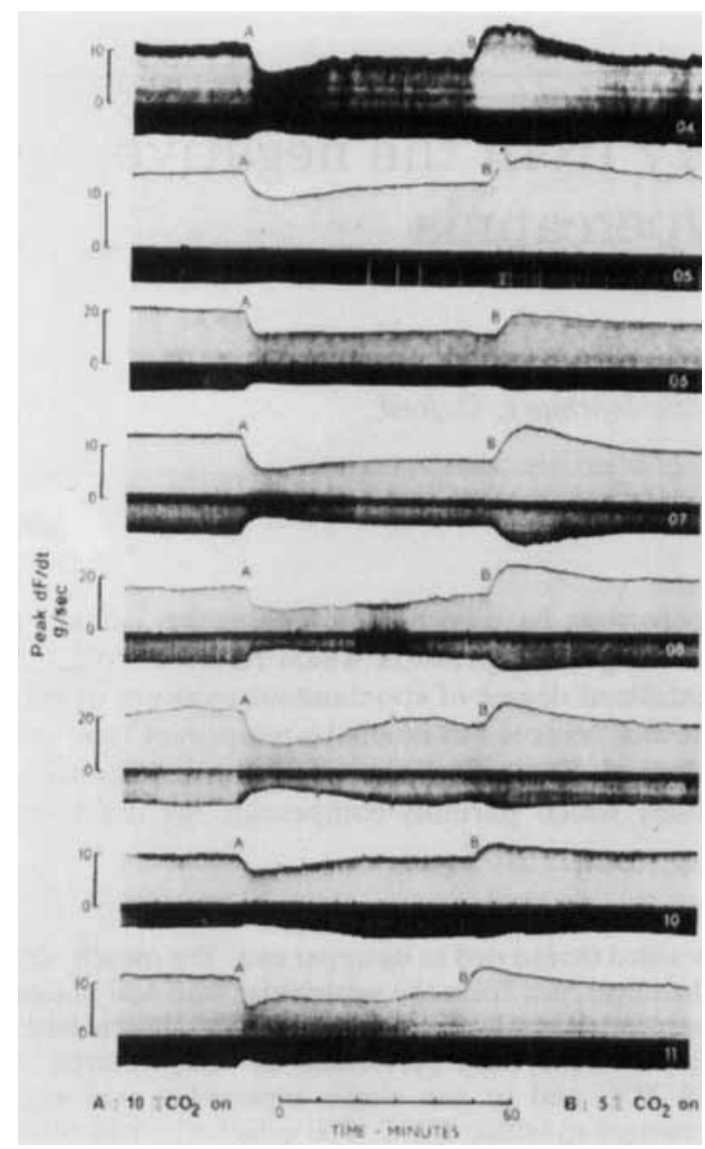

FIG. I The original $d F / d t$ tracings from eight experiments. At point $A$ the $\mathrm{CO}_{2}$ concentration was changed from $4.67 \%$ to $9.79 \%$, and at point B $4.67^{\circ} \% \mathrm{CO}_{2}$ was reintroduced into the muscle bath.
Devices two-channel recorder with which a continuous record could be obtained at slow paper speed. The muscle was stimulated by a Palmer square-wave stimulator through two platinum electrodes placed on either side of the muscle. The rate of stimulation was $30 / \mathrm{min}$ in four experiments and $20 / \mathrm{min}$ in the other five.

Having been placed in the bath and a suitable resting muscle length having been selected, the preparation was allowed to stabilize in the presence of $4.67 \% \mathrm{CO}_{2}$. A slow continuous recording of force development and $\mathrm{dF} / \mathrm{dt}$ was then begun, and continued for $30 \mathrm{~min}$. After this time the high concentration of $\mathrm{CO}_{2}$ was admitted to the bath and changes in performance recorded for $60 \mathrm{~min}$. $4.67 \% \mathrm{CO}_{2}$ was then readmitted and the recording continued for a further $60 \mathrm{~min}$. Intermittent measurements of bath temperature and $\mathrm{pH}$ were made during the course of the experiments, and initial muscle length remained unaltered.

For the purpose of analysing the results, the point just before $9.79 \% \mathrm{CO}_{2}$ was admitted into the bath was taken as the control level, and all previous and subsequent readings were compared with the figures obtained at this moment. Values for active force (= maximum developed force - resting force) in grams and for the peak rate of force development (peak $\mathrm{dF} / \mathrm{dt}$ ) in grams per second were extracted from the records at the following times: the control point; 10, 20, and 30 min before the control point; at the point of maximum depression of contraction and at $10 \mathrm{~min}$ intervals after the introduction of $9.79 \% \mathrm{CO}_{2}$; at the point of maximum increase in contraction and at 10 min intervals after the reintroduction of $4.67 \%$ $\mathrm{CO}_{2}$ into the bath. The statistical significance of changes in active force and in peak $\mathrm{dF} / \mathrm{dt}$ was analysed using a two-tailed paired Student's $t$

T A B LE I

Results, giving means and standard deviations (SD) for active force and peak $d F / d t$ at intervals before and after the control point*

\begin{tabular}{|c|c|c|c|c|c|c|c|}
\hline & \multicolumn{7}{|c|}{ Time from control (min) } \\
\hline & \multicolumn{4}{|c|}{$4.67 \% \mathrm{CO}_{2}$} & \multicolumn{3}{|c|}{$9.79^{\circ} \% \mathrm{CO}_{2}$} \\
\hline & -30 & -20 & -10 & 0 & $\min$ & 10 & 20 \\
\hline \multicolumn{8}{|l|}{ Force (g) } \\
\hline Mean & 4.02 & 3.98 & $4 \cdot 03$ & $4 \cdot 06$ & $2 \cdot 59$ & $2 \cdot 69$ & $2 \cdot 87$ \\
\hline $\mathrm{SD}$ & $1 \cdot 55$ & 1.48 & 1.45 & $1 \cdot 46$ & 0.93 & 0.92 & 0.88 \\
\hline $\mathrm{P}$ & NS & NS & NS & - & $<0.001$ & $<0.01$ & $<0.01$ \\
\hline $\mathrm{P}^{*}$ & $一$ & - & $\rightarrow$ & - & - & NS & $<0.01$ \\
\hline \multicolumn{8}{|c|}{ Peak dFidt (g/sec) } \\
\hline Mean & $13 \cdot 8$ & $13 \cdot 8$ & $13 \cdot 8$ & $13 \cdot 8$ & $8 \cdot 0$ & $8 \cdot 4$ & $9 \cdot 3$ \\
\hline $\mathrm{SD}$ & $3 \cdot 8$ & $3 \cdot 8$ & $3 \cdot 6$ & $3 \cdot 6$ & $2 \cdot 4$ & $2 \cdot 2$ & $2 \cdot 2$ \\
\hline$P$ & NS & NS & NS & 一 & $<0.001$ & $<0.001$ & $<0.01$ \\
\hline$P^{*}$ & - & - & - & - & - & $<0.05$ & $<0.001$ \\
\hline
\end{tabular}

* The statistical significance of changes are shown from control (P) and from the preceeding minimum or maximum value ( $P^{*}$ ). Min. = the point of maximum depression after the beginning of hypercapnia; Max = the point of maximum overshoot after the reintroduction of the control $\mathrm{CO}_{2}$ concentration. 
test for small samples, utilizing one experiment in each muscle, amounting to eight in all.

\section{Results}

In Fig. 1 are displayed the $\mathrm{dF} / \mathrm{dt}$ tracings from eight of our experiments, and the mean changes in peak $\mathrm{dF} / \mathrm{dt}$ and active force at intervals before, during and after the period of hypercapnia are recorded in Table 1 . The tracings commence about $30 \mathrm{~min}$ before the moment when the carbon dioxide concentration in the bath was changed from $4.67 \%$ to $9.79 \%$ (the control point with which all previous and subsequent readings were compared), and during this preliminary period all the preparations were in a fairly stable state. No significant alterations in either active force or peak $\mathrm{dF} / \mathrm{dt}$ were found between controlvalues and readings taken 10,20 , and $30 \mathrm{~min}$ beforehand. The changes in peak $\mathrm{dF} / \mathrm{dt}$ and active force from the control point onwards are shown graphically in Fig. 2 (expressed as per cent of control). After the introduction of $9.79 \% \mathrm{CO}_{2}$ into the bath both peak $\mathrm{dF} / \mathrm{dt}$ and active force were rapidly reduced and reached minimum values 5 to 10 min later, peak $\mathrm{dF} / \mathrm{dt}$ to $57 \%$ of control $(\mathrm{P}<0.001)$ and active force to $63 \%$ of control $(\mathrm{P}<0.001)$. Having reached minimum values both parameters then slowly and spontaneously increased until after about 50 min a new level of stability had been attained. During this period of slow increase in active force and peak $\mathrm{dF} / \mathrm{dt}$ the extracellular $\mathrm{CO}_{2}$ concentration and $\mathrm{pH}$ remained steady. At this stage peak $\mathrm{dF} / \mathrm{dt}$ had increased from $57 \%$ to $81 \%$ of control $(\mathrm{P}<0.001)$, and active force from $63 \%$ to $84 \%$ of control $(\mathrm{P}<0.01)$, although at this time both parameters were still below their original control values $(\mathrm{P}<0.01)$. After $60 \mathrm{~min}$ of hypercapnia $4.67 \% \mathrm{CO}_{2}$ was reintroduced into the bath, and both peak $\mathrm{dF} / \mathrm{dt}$ and active force rapidly increased by the same amount as they had fallen after the introduction of the high $\mathrm{CO}_{2}$ concentration. Combined with the slow compensatory increases which had occurred during the period of hypercapnia, this resulted in a marked overshoot of peak $\mathrm{dF} / \mathrm{dt}$ to $118 \%$ and of active force to $120 \%$ of control. Some $50 \mathrm{~min}$ later both values had returned approximately to control levels.

The mean $\mathrm{pH}$ of the bathing solution before the onset of hypercapnia was $7.400 \quad(\mathrm{SD}=$ $0.010)$. Ten minutes after the introduction of $9.79 \% \mathrm{CO}_{2}$ into the bath the mean $\mathrm{pH}$ was $7.105(\mathrm{SD}=0.017)$, and after $50 \mathrm{~min}$ was 7.108 $(\mathrm{SD}=0.014)$. After the reintroduction of $4.67 \%$ $\mathrm{CO}_{2}$ the mean $\mathrm{pH}$ was $7.406(\mathrm{SD}=0.013)$ after $10 \mathrm{~min}$ and $7.412(\mathrm{SD}=0.015)$ after $30 \mathrm{~min}$.

At no time during the experiments were any consistent changes in resting force observed. Figure 3 shows a fast record of single contractions taken before and during hypercapnia in one preparation, and it can be seen that during this period changes in developed force and peak $\mathrm{dF} /$ $\mathrm{dt}$ are unaccompanied by any alteration in resting force.

\section{Discussion}

The primary effect of a high $\mathrm{CO}_{2}$ concentration on the mechanical performance of the myo-

\begin{tabular}{|c|c|c|c|c|c|c|c|c|c|c|}
\hline \multicolumn{11}{|c|}{ Time from control (min) } \\
\hline \multicolumn{4}{|c|}{$9.79 \% \mathrm{CO}_{2}$} & \multicolumn{7}{|c|}{$4.67 \% \mathrm{CO}_{2}$} \\
\hline 30 & 40 & 50 & 60 & $\operatorname{Max}$ & 70 & 80 & 90 & 100 & 110 & 120 \\
\hline $\begin{aligned} & 3.05 \\
& 0.88 \\
< & 0.01 \\
< & 0.001\end{aligned}$ & $\begin{aligned} & 3.13 \\
& 0.88 \\
< & 0.01 \\
< & 0.001\end{aligned}$ & $\begin{aligned} & 3.30 \\
& 0.89 \\
&< 0.01 \\
&< 0.001\end{aligned}$ & $\begin{array}{r}3.39 \\
1.10 \\
<0.01 \\
<0.01\end{array}$ & $\begin{array}{r}4.86 \\
1.74 \\
<0.02 \\
-\end{array}$ & $\begin{array}{c}4.84 \\
1.67 \\
<0.02 \\
\text { NS }\end{array}$ & $\begin{array}{c}4.56 \\
1.63 \\
\text { NS } \\
<0.01\end{array}$ & $\begin{array}{c}4.27 \\
1.55 \\
\mathrm{NS} \\
<0.01\end{array}$ & $\begin{array}{c}4.15 \\
1.59 \\
\text { NS } \\
<0.01\end{array}$ & $\begin{array}{c}4 \cdot 10 \\
1 \cdot 54 \\
\text { NS } \\
<0.01\end{array}$ & $\begin{array}{c}4.02 \\
1.46 \\
\text { NS } \\
<0.01\end{array}$ \\
\hline $\begin{aligned} & 9.8 \\
& 2.2 \\
&< 0.01 \\
&< 0.001\end{aligned}$ & $\begin{array}{c}10.1 \\
2.2 \\
<0.01 \\
<0.001\end{array}$ & $\begin{array}{c}10.8 \\
2.4 \\
<0.01 \\
<0.001\end{array}$ & $\begin{array}{c}11 \cdot 1 \\
2.5 \\
<0.01 \\
<0.001\end{array}$ & $\begin{array}{c}17.0 \\
4.5 \\
<0.01 \\
-\end{array}$ & $\begin{array}{r}16.6 \\
4.6 \\
<0.05 \\
<0.01\end{array}$ & $\begin{array}{c}15 \cdot 3 \\
4 \cdot 2 \\
\text { NS } \\
<0 \cdot 001\end{array}$ & $\begin{array}{c}14.1 \\
3.8 \\
N S \\
<0.001\end{array}$ & $\begin{array}{c}13.7 \\
4.0 \\
\text { NS } \\
<0.001\end{array}$ & $\begin{array}{c}13.4 \\
3.9 \\
\text { NS } \\
<0.001\end{array}$ & $\begin{array}{c}13.2 \\
3.7 \\
N S \\
<0.00\end{array}$ \\
\hline
\end{tabular}




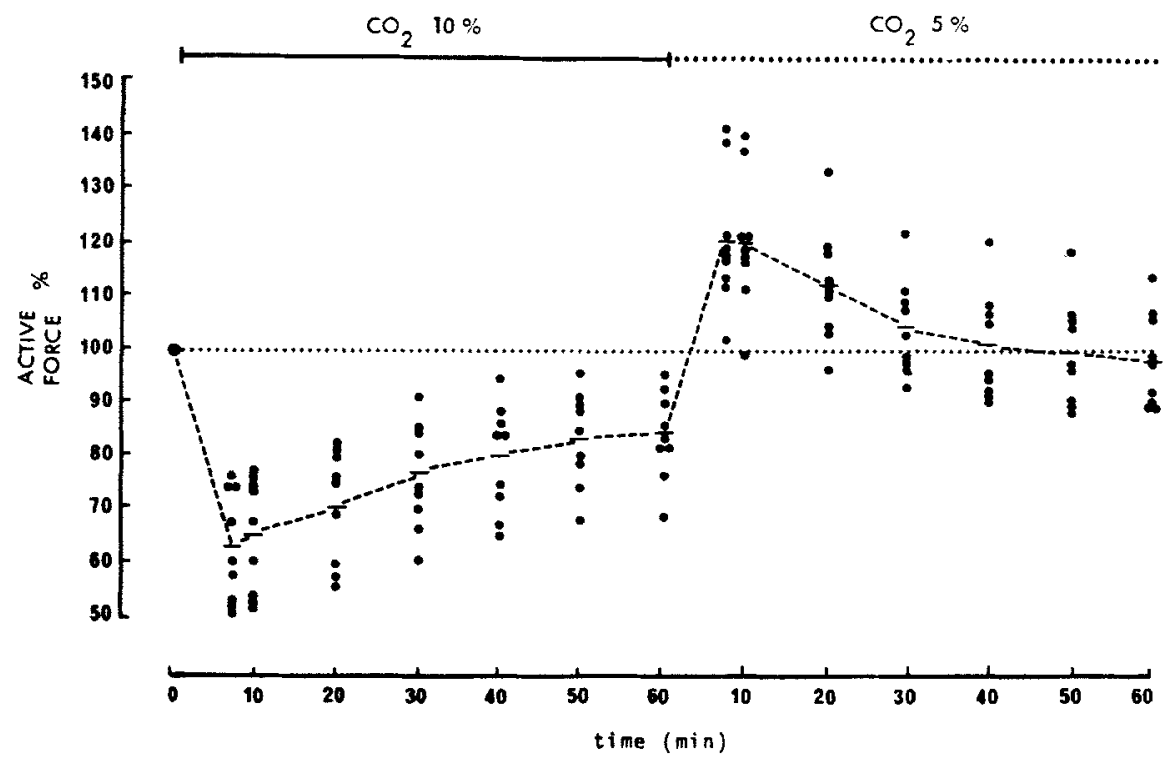

FIG. 2 a Alterations in active force during the course of the experiments (per cent of control).

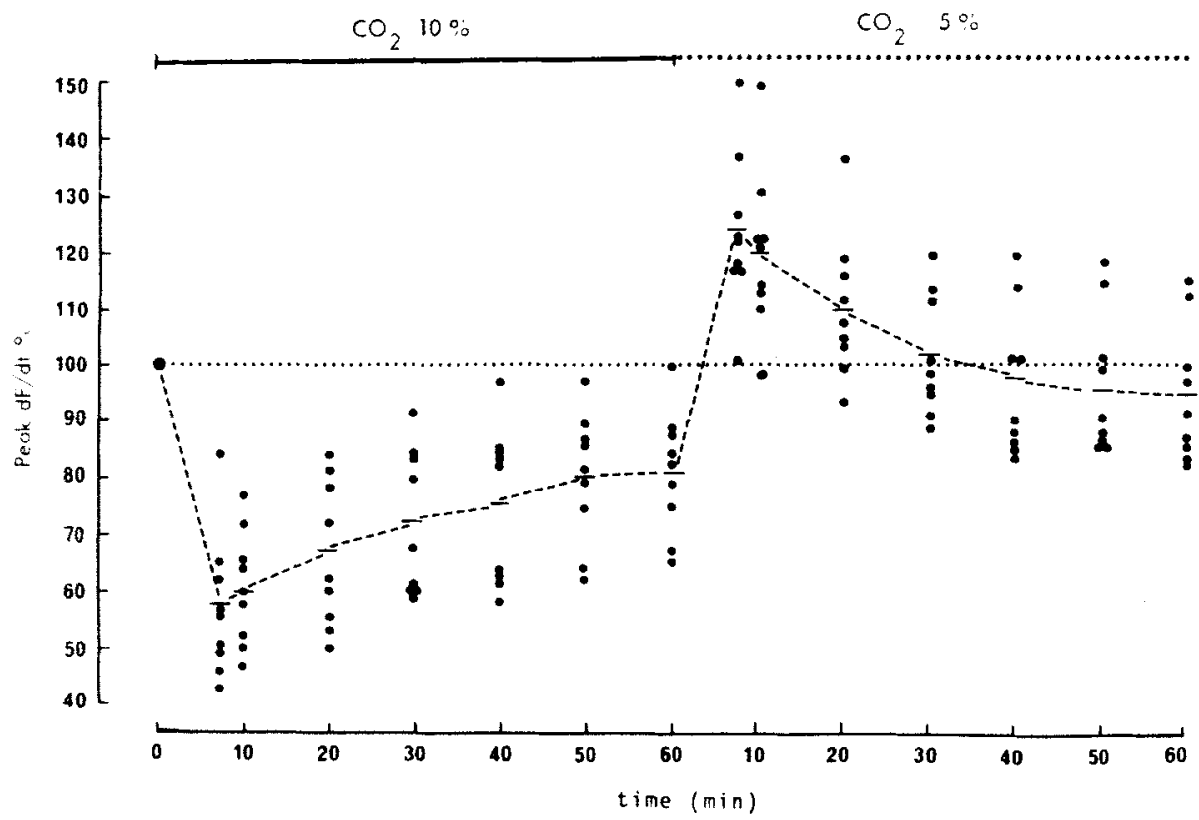

FlG. $2 \mathrm{~b}$ Alterations in peak $d F / d t$ (per cent of control). All points obtained at the indicated time intervals have been plotted. The short horizontal lines at each interval represent the means of the individual values.

cardium is one of depression (Nahas, 1957; McElroy et at., 1958; $\mathrm{Ng}$ et al., 1967; Noble et al., 1967: Pannier and Leusen, 1968). In the intact animal acute hypercapnia is accompanied by an increase in sympathetic nervous activity (Nahas and Steinsland, 1968) which compensates, or even overcompensates, for the depressant effect of $\mathrm{CO}_{2}$ (Boniface and Brown, 1953; Nahas and Cavert, 1957; Manley, Nash, and Woodbury, 1964). It has also been suggested that hydrocortisone is able to reverse hypercapnic myocardial depression (Nahas, 1957). 


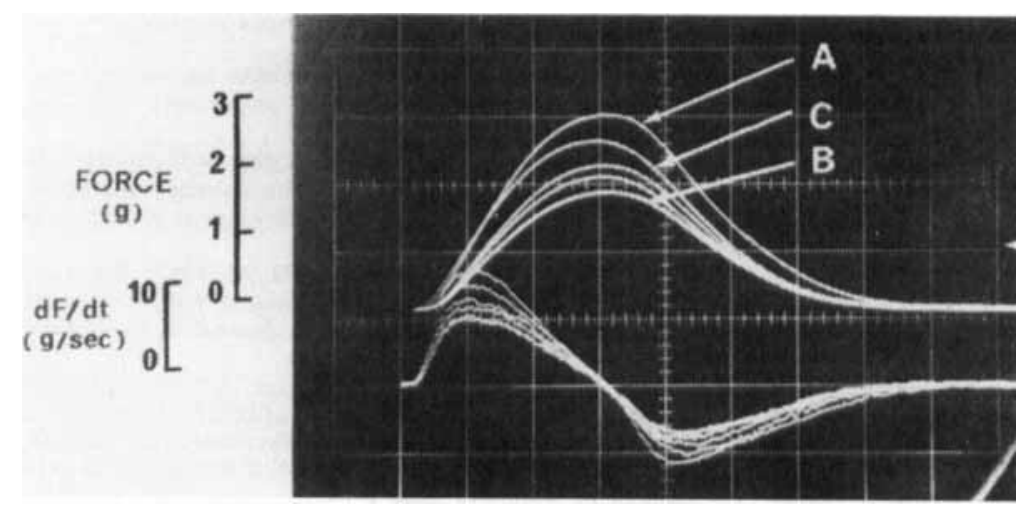

FIG. 3 Fast tracings of force and $d F / d t$ during prolonged hypercapnia in one preparation. Curve A: normocapnia. Curve B: 10 min after the onset of hypercapnia. Curve $\mathrm{C}$ : after $50 \mathrm{~min}$ of hypercapnia. Corresponding changes are seen in the $d F / d t$ tracing. For technical reasons the force curves show some variation in placement on the time scale $(1$ large square $=$ $100 \mathrm{msec}$ ).

In order to demonstrate whether recovery from myocardial depression due to acute hypercapnia is entirely due to outside factors, or whether heart muscle per se is able to play some part in the phenomenon, accurate control of other factors which may influence myocardial performance, such as initial fibre length, heart rate, extracellular electrolyte concentrations and sympathetic tone, must be achieved. We have been unable to find any published work in which these criteria have been completely satisfied. Young, Monroe, and Craig (1960), working with a standard canine heart-lung preparation, reported that the immediate response to a rise in $\mathrm{CO}_{2}$ was a fall in cardiac output, but that during longer periods of hypercapnia a considerable spontaneous increase in cardiac output occurred, even though the right atrial filling pressure of the heart remained constant. Although no attempt was made to control the heart rate, they stated that no changes in the ECG occurred during this time, except for 'slowing of the heart rate with high $\mathrm{CO}_{2}$ mixtures', suggesting that the spontaneous increase in output was due to a rise in the stroke volume of the preparation. Nejad and Ogden (1967), recording the changes in left atrial pressure at a constant stroke work during hypercapnia in the dog heart-lung preparation, found that a steep rise in pressure occurred soon after raising the arterial $\mathrm{PCO}_{2}$, followed by a spontaneous fall towards control level, again suggesting myocardial recovery from the effects of acute hypercapnia. No attempt was made to control the heart rate, which may itself influence the left atrial pressure.

In our preparation rate of contraction, resting muscle length, extracellular electrolyte concentrations, and external hormonal and nervous factors were unchanged or absent throughout the ex- periments. Nevertheless, both peak $\mathrm{dF} / \mathrm{dt}$ and active force showed considerable recovery from the initial period of depression after the onset of hypercapnia. The results indicate that a significant part of the recovery of myocardial performance which occurs during prolonged hypercapnia can be attributed to a compensatory process arising within the muscle itself.

There is no doubt that, in the intact animal, increased sympathetic activity plays an important rôle in protecting the heart against the detrimental effects of a high $\mathrm{CO}_{2}$ concentration (Morris and Millar, 1962). In our experiments the time course of recovery was slower than has been reported previously under conditions which allowed the sympathetic response to $\mathrm{CO}_{2}$ to play its part, and it may be that the sympathetic nervous system has its most important compensating rôle early in a period of hypercapnia. Once intrinsic myocardial recovery has been completed, the need for sympathetic aid in maintaining myocardial performance is correspondingly reduced. It may not, however, be justified to extrapolate the results obtained in our preparation to the intact animal as regards the time course of the events we have observed.

The mechanism by which the myocardium is able to reverse the acute effects of $\mathrm{CO}_{2}$ are unknown. Some of the many possibilities are:

1. The spontaneous return of intracellular $\mathrm{pH}$ towards normal in the face of a continuing extracellular acidosis.

2. Alterations in calcium distribution within the muscle cells or across the cell membrane.

3. The release of intramyocardial noradrenaline stores, as has been suggested by Smith and Corbascio (1966) during metabolic acidosis.

4. Alterations in the dynamic compliance of the series elastic element. 


\section{References}

Boniface, K. J., and Brown. J. M. (1953). Effect of carbon dioxide excess on contractile force of heart, in situ. American Journal of Physiology, 172, 752-756.

Caress, D. L.. Kissack, A. S., Slovin, A. J., and Stuckey, J. H. (1968). The effect of respiratory and metabolic acidosis on myocardial contractility. Journal of Thoracic and Cardiovascular Surgery, 56, 571-577.

Gersh, B. J., Hahn, C. E. W., and Prys-Roberts, C. (1971). Physical criteria for measurement of left ventricular pressure and its first derivative. Cardiovascular Research, 5 , $32-40$.

McElroy, W. T., Jr., Gerdes, A. J., and Brown, E. B., Jr (1958). Effects of $\mathrm{CO}_{2}$, bicarbonate and $\mathrm{pH}$ on the performance of isolated perfused guinea pig hearts. American Journal of Physiology, 195, 412-416.

Manley, E. S., Jr., Nash, C. B., and Woodbury, R. A. (1964). Cardiovascular responses to severe hypercapnia of short duration. American Journal of Physiology, 207, 634-640.

Morris, M. E., and Millar, R. A. (1962). Blood pH/plasma catecholamine relationships: respiratory acidosis. British Journal of Anaesthesia, 34, 672-681.

Nahas, G. G. (1957). Effect of hydrocortisone on acidotic failure of the isolated heart. Circulation Research, $\mathbf{5}$ 489-492.

Nahas, G. G., and Cavert, H. M. (1957). Cardiac depressant effect of $\mathrm{CO}_{2}$ and its reversal. American Journal of Physio$\log y, 190,483-491$.

Nahas, G. G., and Steinsland, O. S. (1968). Increased rate of catecholamine synthesis during respiratory acidosis. Respiration Physiology, 5, 108-117.

Nejad, N. S., and Ogden, E. (1967). Effect of blood pH and $\mathrm{CO}_{2}$ tension on performance of the heart-lung preparation. Proceedings of the Society of Experimental Biology and Medicine, 126, 771-776.

Ng, M. L., Levy, M. N., and Zieske, H. A. (1967). Effects of changes of $\mathrm{pH}$ and of carbon dioxide tension on left ventricular performance. American Journal of Physiology, 213, $115-120$

Noble, M. I. M., Trenchard, D., and Guz, A. (1967). Effect of changes in $\mathrm{Pa}_{\mathrm{CO}}$ and $\mathrm{Pa}_{\mathrm{O}}$ on cardiac performance in conscious dogs. Journal of Applied Physiology, 22, 147-152.

Pannier, J. L., and Leusen, I. (1968). Contraction characteristics of papillary muscle during changes in acid-base composition of the bathing-fluid. Archives Internationales de Physiologie et de Biochimie, 76, 624-634.

Smith, N. T., and Corbascio, A. N. (1966). Myocardial resistance to metabolic acidosis. Archives of Surgery, 92, 892-897.

Young, D. T., Monroe, E. W., and Craige, E. (1960). Relationship between cardiac toxicity of $K$ and acute alterations of blood $\mathrm{pH}$ and $\mathrm{pCO}_{2}$. American Journal of Physiology, 199, 759-764. 